\title{
Analysis of Felder-Solomon Index of Learning Styles of Students from Management and Engineering at the University of Mauritius
}

\author{
Maleika Heenaye*, Baby Ashwin Gobin, Naushad Ali Mamode Khan \\ University of Mauritius, Mauritius \\ *m.mamodekhan@uom.ac.mu
}

\begin{abstract}
No prior investigations have been made on the learning styles of students from different fields studying the same module at the University of Mauritius. Techniques have to be explored to depict their learning styles, which can lead to a more effective teaching. In this work, students from faculty of management and faculty of engineering studying one of the Information Technology modules at the University of Mauritius were being studied and their learning styles were being deduced through FelderSolomon index of learning (ILS) questionnaire. The data obtained from the questionnaire has been analyzed and it was concluded that students from both faculties have different learning styles. While understanding these differences, there is a better chance to meet diverse learning needs of both groups of students.
\end{abstract}

Keywords: Learning styles, Felder-Solomon learning style model, Management students, Engineering students, Pearson correlation

\section{Introduction}

The ways in which an individual characteristically acquires, retains, and retrieves information are collectively termed the individual's learning style. Students learn in many ways-by seeing and hearing; reflecting and acting; reasoning logically and intuitively; memorizing and visualizing (Felder, 1995).Some popular learning styles are auditory, visual, tactual and kinaesthetic. Auditory learners like the teacher to provide verbal instructions and find it easy to learn by listening. Visual learners need to see the teacher's body language and expression. They mostly recognize words by sight. However, they are easily distracted by movement or action. Tactual learners like to draw or doodle to remember and do best when they take notes during lectures. As for the kinaesthetic learner, they do best when they are involved or active and they learn best while moving. In order to figure out the learning style of an individual, different learning style instruments are used. Learning styles have been extensively discussed in the educational psychology literature (Felder, 1995). Students have different levels of motivation, different attitudes about teaching and learning, and different responses to specific classroom environments and instructional practices. The more thoroughly instructors understand the differences, the better chance they have of meeting the diverse learning needs of all of their students (Felder and Brent, 2005). In this paper, a thorough study was carried out on Engineering and management students in order to determine their learning styles. In the recent years, there is a decline interest in the Engineering among high school students and this has led to steep enrolment decreases in many engineering programs.

\section{Literature Review}

Learning style is a concept derived from psychology and refers to the way individuals prefer to process new information and strategies they adopt for effective learning. Felder \& Brent (2005) define learning styles as characteristic cognitive, affective, and psychological behaviours that serve as relatively stable indicators of how learners perceive, interact with, and respond to the learning environment. There are different types of learning style models that have been presented in literature. Some of them are the VARK model, the ILS, model, Kolb learning style, Gregorc Style Delineator and Dunn and Dunn learning styles. Instruments are provided for all these models, which can be used to assess a learner's learning style. The VARK Model is a sensory model that is an extension of the earlier neuro-linguistic model. The acronym VARK stands for Visual (V), Aural (A), Read/Write (R), and Kinaesthetic (K). Fleming (2001) defines learning style as "an individual's characteristics and preferred ways of gathering, organizing, and thinking about information. VARK is in the category of instructional preference because it deals with perceptual modes. It is focused on the different ways that we take in and give out information". The only perceptual modes, or senses, it does not address are taste and smell. The VARK Inventory provides 
metrics in each of the four perceptual modes, with individuals having preferences for anywhere from one to all four. Individual students have relative preferences along each of the four perceptual modes but can learn to function in the other modes (Hawk and Shah, 2007. The free VARK questionnaire (www.varklearn.com) offers thirteen statements that describe a situation and asks the respondent to pick one or more of three or four actions that the respondent would take. Each action corresponds with a VARK Learning Style preference. The total of all four scores ranges from 13 to 48, with individuals having a preference for one, two, three, or all four of the learning channels. Students and faculty can selfadminister, self-score, and self-interpret the VARK Inventory. There are also differences in learning approaches for the four VARK Learning Styles. The learning preferences with respect to each type of learner are shown in the Table 1.

Table 1: Characteristics of the four dimensions of VARK (Felder and Silverman 1995, Felder, 1993)

\begin{tabular}{|c|c|}
\hline Type of Learner & Learning Preferences \\
\hline Visual & $\begin{array}{l}\text { maps, charts, graphs, diagrams, brochures, flow charts, highlighters, different } \\
\text { colours, pictures, word pictures, and different spatial arrangements }\end{array}$ \\
\hline Aural & $\begin{array}{l}\text { explain new ideas to others, discuss topics with other students and their teachers, } \\
\text { use a tape recorder, attend lectures and discussion groups, and use stories and jokes }\end{array}$ \\
\hline Read/Write & $\begin{array}{l}\text { lists, essays, reports, textbooks, definitions, printed handouts, readings, manuals, } \\
\text { web pages, and taking notes }\end{array}$ \\
\hline $\begin{array}{l}\text { Kinaesthetic } \\
\text { learners }\end{array}$ & $\begin{array}{l}\text { like field trips, trial and error, doing things to understand them, laboratories, recipes } \\
\text { and solutions to problems, hands-on approaches, using their senses, and collections } \\
\text { of samples }\end{array}$ \\
\hline
\end{tabular}

Felder and Silverman (1988) learning style (ILS) is another mode, originating in the engineering sciences, defines learning style as the characteristic strengths and preferences in the ways individuals take in and process information. It asserts that individuals have preferences along five bipolar continua: the ActiveReflective, the Sensing-Intuitive, the Verbal-Visual, the Sequential-Global, and the Intuitive-Deductive. The Index of Learning Styles (ILS) provides metrics for all but the Intuitive-Deductive dimension, with scores showing the strength of an individual's preference for the indicated continuum. Individual students have relative preferences along each of the four but can learn to function in the other direction. The ILS is a free, 44-item questionnaire (available from www.ncsu.edu/effective teaching) that asks the respondent to choose one of two endings to a sentence that focuses on some aspect of learning. Scoring is $1,3,5,7,9$, and 11 , with 1 and 3 showing a balance along the continuum, 5 and 7 showing a moderate preference for one end of the continuum, and 9 and 11 a strong preference for one end or the other. The students and faculty can self-administer, self-score, and self-interpret this inventory. Active learners prefer doing things, particularly in groups. Reflective learners work better on their own, with time to think about the task before doing it. Sensing learners like facts, data, and experimentation and work well with detail. Intuiting learners prefer ideas and theories, particularly when they can grasp new ideas and innovation. Verbal learners like to hear their information and engage in discussion, especially when they can speak and hear their own words. Visual learners like words, pictures, symbols, flow charts, diagrams, and reading books. Sequential learners prefer linear reasoning, systematic procedures, and material that come to them in a steady stream. Global learners are strong integrators and synthesizers, making intuitive discoveries and connections to see the overall system or pattern (Hawk and Shah, 2007).

Felder and Silverman (1988) discuss a number of teaching approaches useful to match the learning preferences that emerge from the use of the ILS as shown in Table 2. Active learners like trying something out, doing it, and seeing if it works, particularly in groups. Reflective learners want to think it through first, take notes in class, and work alone. Intuitions like discovering possibilities, grasping new concepts, and working with abstractions. Visual learners want to see pictures, diagrams, flow charts, films, and demonstrations. Verbal learners like hearing and discussing information, taping lectures, and explaining themselves. Sequential learners like to move step-by-step through the material, progress logically to the solution to a problem. Global learners want to see the big picture, take in information randomly before putting it all together, and work intuitively (Hawk and Shah, 2007). Among other learning styles instrument that are used, Kolb learning style indicator, Gregorc style delineator and, Dunn and Dunn learning styles instruments are used. Kolb learning style is an experiential model, which defines learning as "the process whereby knowledge is created through the transformation of experience". Learning is a holistic set of processes that are continuous, with a lesser emphasis on outcomes. The model asserts a four-mode or four-process learning cycle that covers and generally starts with Concrete Experience (CE), moving to Reflective Observation (RO), then to Abstract Conceptualization (AC), and finally to Active 
Experimentation (AE), with the most effective and complete learning taking place when learning activities embrace all four modes. However, depending on the individual's preferences, learning may start at any one of the other modes in the cycle. Kolb describes $\mathrm{CE}$ and $\mathrm{AC}$ as bipolar on a continuum and orthogonal to a second bipolar continuum of RO and AE. Individual learning styles result from a combination of two adjacent mode preferences in the experiential learning cycle leading to four basic learning styles: Diverger (CE and RO), Assimilator (RO and AC), Converger (AC and AE), and Accommodator (AE and CE). Individuals have a preference for one of the four learning styles but can and should learn to use the other modes. Figure 1 presents the Kolb Experiential Learning Cycle (adapted from Kolb, 1984). The Kolb Learning Style Inventory (LSI) is a commercially available questionnaire (www.learningfromexperience.com) with twelve items where respondents rank-order four sentence endings that correspond to the four learning modes. Students and faculty can self-administer, self-score, and self-interpret the ILS (Hawk and Shah, 2007).

Table 2: Characteristics of the four dimensions of ILS (Felder and Silverman 1988, Felder, 1993) Complementary learning styles

\section{Sensing}

- Draws on physical sensation

- Practical and observing

- Prefer the concrete: facts and data

- Prefer repetition

Visual

- 'Show me how'

- Prefer pictures and diagrams

Active

- 'Let's try it out'

- Process information by physical activity

- Learn by working with others

Sequential

- Understand in continual and incremental steps

- Linear reasoning process

- Convergent thinking and analysis
Intuitive

- Draws on insight

- Imaginative and interpretive

- Prefer the abstract: theory and modelling

- Prefer variation

Verbal

- 'Tell me how'

- Prefer written and spoken explanations

Reflective

- 'Let's think it through'

- Process information introspectively

- Learn by working alone or in pairs

Global

- Understand in large leaps

- Tacit reasoning process

- System thinking and synthesis

\section{Figure 1: Kolb Learning Style}

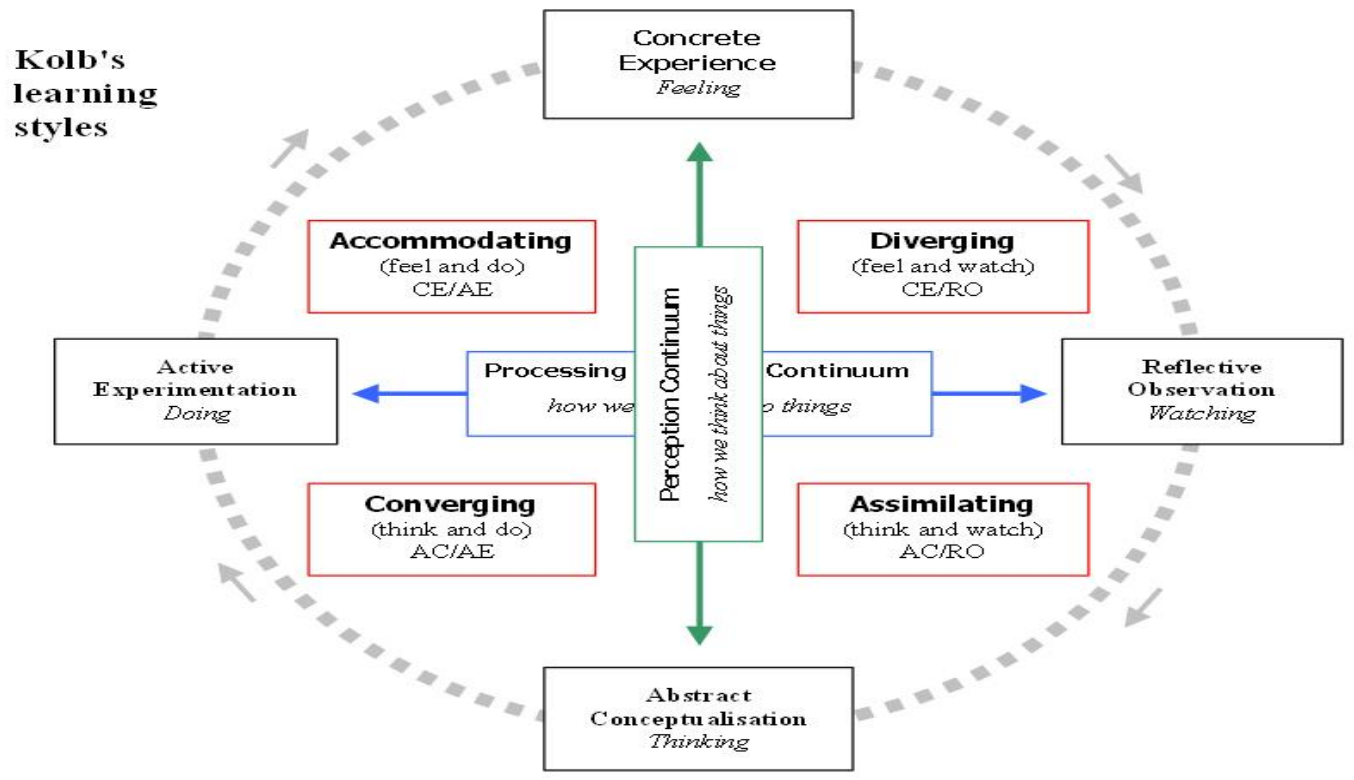

Another learning style, which is the Gregorc Learning/Teaching Style Model, is based in phenomenological research as well as Kolb's experiential learning cycle, defines learning style as "distinctive and observable behaviours that provide clues about the mediation abilities of individuals and how their minds relate to the world and, therefore, how they learn" (Gregorc, 1979) . Gregorc (1985) claims that individuals have natural predispositions for learning along four bipolar, continuous mind qualities that function as mediators as individuals learn from and act upon their environments. Those mind qualities are abstract and concrete perception, sequential and random ordering, deductive and 
inductive processing, and separative and associative relationships. The Gregorc Style Delineator (GSD) provides metrics on the first two qualities, perception and ordering, giving an individual a score from 10 to 40 in each of four learning styles of Concrete-Sequential (CS), Abstract-Sequential (AS), AbstractRandom (AR), and Concrete-Random (CR), with a maximum of 100 points for all four. Gregorc describes concrete and abstract as orthogonal to Sequential and Random. Although the scores indicate the individual's innate dispositions for one, two, three, or all of the styles, individuals can improve their use of the mind qualities that do not score high. The GSD is commercially available (www.gregorc.com) and asks the respondent to rank order ten sets of four words that correspond to the four poles of the two mind qualities. Students and faculty can self-administer, self-score, and self-interpret the GSD. Gregorc (1979, 1985) provides only limited research on the validity and reliability of his instrument [Hawk and Shah, 2007, Felder and Silverman (1988) and Gregorc (1985)]. In the Dunn and Dunn Learning Style Model (1990) learning style is defined as "the way in which individuals begin to concentrate on, process, internalize, and retain new and difficult information" (Gregorc (1979). Dunn et al. (1982) suggest that there are five learning style stimuli and several elements within each stimulus. The five stimuli and their respective elements are Environmental (sound, light, temperature, and room design), Emotional (motivation, persistence, responsibility, and structure), sociological (learning alone, in a pair, with peers, with a teacher, and mixed), physiological (perceptual, intake while learning, chronological energy pattern, and mobility needs), and Psychological Processing (global or analytic, hemisphericity, and impulsive or reflective). Dunn et al. (1982) model is a commercially available questionnaire (www. humanresources.com) that offers a set of 100 questions covering all five stimuli and their respective elements. Scores range from 20 to 80, with 40 to 60 reflecting a low or balanced preference for the two ends of each of the 20 elements, and 20 to 40 or 60 to 80 reflecting a stronger preference for the indicated polar end. Students and faculty can self-administer, self-score, and self-interpret the PEPS if purchased online [Hawk and Shah (2007), Dunn et al. (1982)].

\section{Methodology}

As mentioned earlier, this work is based on analysing the learning styles of management and engineering students at the University of Mauritius following the same IT module. ILS questionnaire were administered with a group of 120 students from BSc (Hons) Management and a group of 120 Students from BSc (Hons) Computer Science. The questionnaires were placed online and students were given a lapse of 2 weeks to answer to the questions.

\section{Findings and Analysis}

ILS Scale: The ILS questionnaire findings were analysed and compiled using the ILS scale. The scores were plotted for both groups as shown in the diagrams below:

Figure 2: ILS Scale for Computer Science student (CSE)

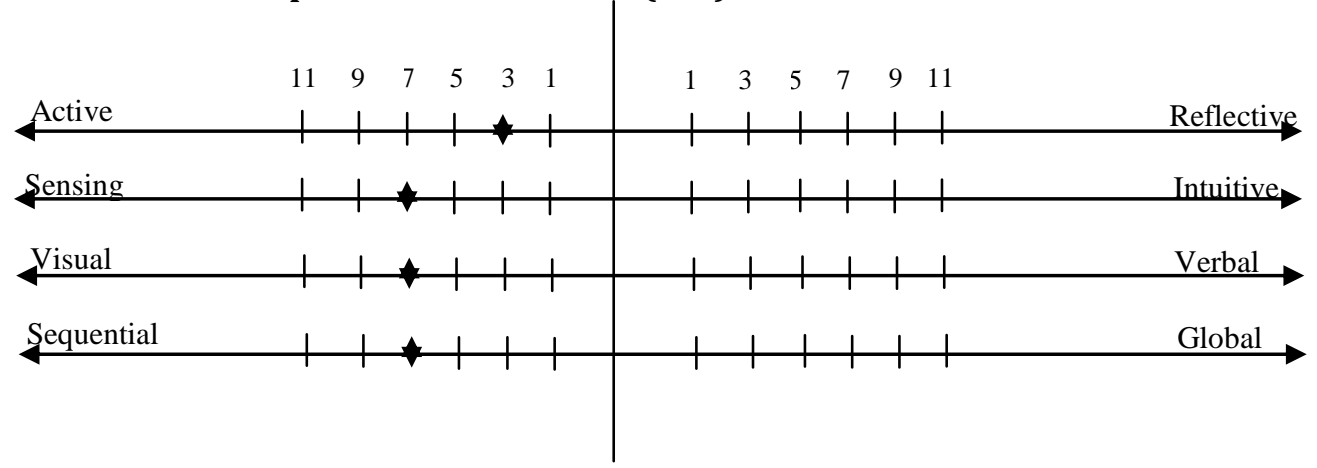

Figure 3: ILS Scale for Management students (MGT)

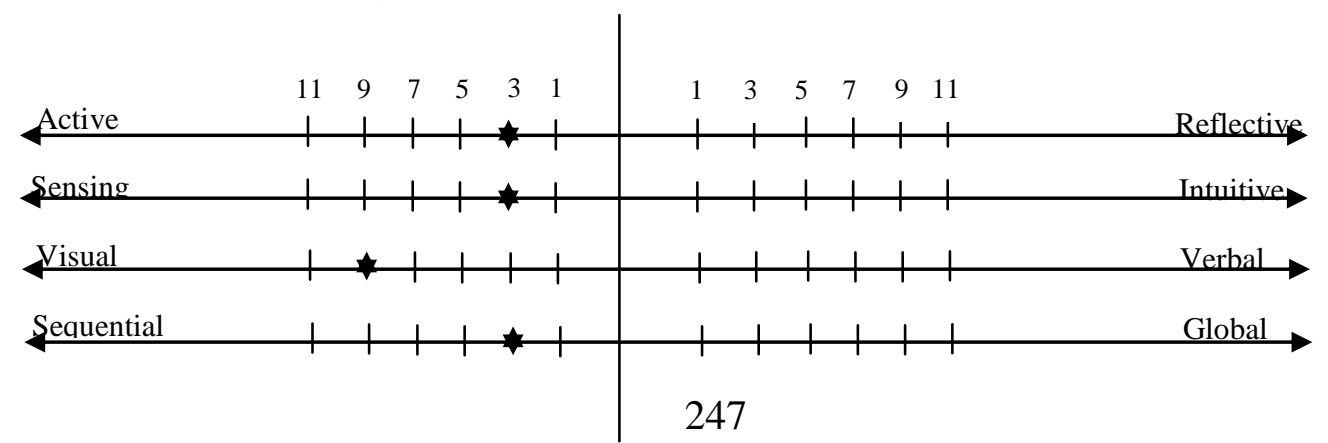


After plotting the score for the management and CSE group, it was found that score 3 was obtained on the left hand side for Active/Reflective option, which means that the students can have a balanced continuum along this axis. For the option Sensing/Intuitive, again a score 3 was obtained on the left hand side for MGT group and score 7 was obtained for CSE group. Thus, CSE group seems to have a moderate preference for sensing compared to management students. Students of MGT have scored 9 (strong preference) and CSE students have scored 7 (moderate preference) on the left hand side for the option Visual/Verbal. As for the option Sequential/Global, a score 3 was obtained for MGT students and a score 7 was obtained for CSE students.

Mean and ANOVA test: To further analyse the learning styles of the students using the data obtained from the ILS questionnaire, the means for the different categories were calculated for both batches. The table below shows the result for the Computer Science students:

Table 3: Mean values for student for BSc (Hons) Computer Science

\begin{tabular}{lllll}
\hline Learning Styles & Active & Sensing & Visual & Sequential \\
\hline Mean & 50.2 & 53.5 & 56 & 51.2 \\
\hline
\end{tabular}

Based on ANOVA F-test statistic using software R 1.6.1, we have obtained $f^{*}=4.121>f_{0.05,3,30}$. This implies the test is significant and thus the mean score of the Computer Science students under the different learning styles quite differ. We note the mean number of visual learners after responding the 11 questions pertained to visual learning is slightly higher than for the others under their respective categories. Going a step further, by applying pair wise two sample t-tests and the Bonferroni's test statistic, we note a significant difference between active learning and visual learning, active and sensing learning and active and sequential learning while there is no significant difference between visual, sensing and sequential. This leads us to the conclusion that Computer Science students are more towards visual, sequential and sensing learning than active learning. To demonstrate the degree of linear relationship among these three learning styles, we compute the Pearson correlation matrix.

Table 4: Pearson Correlation matrix for BSc (Hons) Computer Science

\begin{tabular}{lllll}
\hline & Active & Sensing & Visual & Sequential \\
\hline Active & 1 & -0.32 & -0.33 & 0.10 \\
Sensing & -0.32 & 1 & 0.75 & 0.66 \\
Visual & -0.33 & 0.75 & 1 & 0.82 \\
Sequential & 0.10 & 0.66 & 0.82 & 1 \\
\hline
\end{tabular}

From the above table, we note a strong relationship between the visual-sequential learners followed by visual sensing and sequential-sensing, thus confirming the conclusions above.

In the case of the management students, we obtain an $f^{*}=4.234>f_{0.05,3,30}$ which implies significant changes among the learning styles.

Table 5: Mean values for student for BSc (Hons) Management

\begin{tabular}{lllll}
\hline Learning Styles & Active & Sensing & Visual & Sequential \\
\hline Mean & 58.8 & 60.5 & 69.1 & 55.8 \\
& & & & \\
\hline
\end{tabular}

By applying a 2-sample t testing, we note a significant difference between visual and active learning styles and visual and sequential learning styles. As for sensing and visual, the test is insignificant. This means that for management students there is a more preference towards the visual style followed by sensing learning style. This can be confirmed in the following correlation matrix which demonstrates a strong positive relation between Visual and Sensing whereas a mild correlation between Visual and the other learning styles. 
Table 6: Pearson Correlation matrix for BSc (Hons) Management

\begin{tabular}{lllll}
\hline & Active & Sensing & Visual & Sequential \\
\hline Active & 1 & -0.15 & -0.25 & 0.14 \\
Sensing & -0.15 & 1 & 0.72 & 0.23 \\
Visual & -0.25 & 0.72 & 1 & -0.26 \\
Sequential & 0.14 & 0.23 & -0.26 & 1 \\
\hline
\end{tabular}

We have also compared the p-values between the two groups under same category

Table 7: p- values for CSE and MGT

\begin{tabular}{lllll}
\hline CSE/MGT & Active & Sensing & Visual & Sequential \\
\hline Active & 0.00008 & & & \\
Sensing & & 0.00005 & 0.00009 & \\
Visual & & & 0.0003925 \\
Sequential & & & \\
\hline
\end{tabular}

At $5 \%$ significance level, we conclude that there is no significance between any styles and thus management-learning styles are different from Computer Science learning styles.

\section{Conclusion}

This paper shows an analysis of the learning styles of management and computer science students from two different faculties at the University of Mauritius for the same module. According to the results obtained, both groups have distinct learning style, which poses a challenge for the teaching style that need to be used to cater for their learning needs. Computer Science students have a moderate preference for visual, sensing and sequential. According to the Pearson correlation matrix, Management students have a strong for visual and sensing. However, they have a low preference for sequential learning compared to Computer Science students.

\section{References}

Dunn, R., Dunn, K. \& Price, G. E. (1982). Productivity environmental preference survey. Lawrence, KS: Price Systems.

Felder, R. \& Brent, R. (2005). Understanding Student Differences. Journal of Engineering Education, 94(1), 57-72.

Felder, R. (1995). Learning and Teaching Styles in Foreign and Second Language Education. Foreign Language Annals, 28(1), 21-31.

Felder, R. M. (1993). Reaching the Second Tier: Learning and Teaching Styles in College Science Education. J. College Science Teaching, 23(5), 286-290.

Felder, R. M. \& Silverman, L. K. (1988). Learning styles and teaching styles in engineering education. Engineering Education, 78(7), 674-681.

Fleming, N. D. (2001). Teaching and learning styles: VARK strategies. Christchurch, New Zealand: N.D. Fleming.

Gregorc, A. F. (1979). Learning/teaching styles: Their nature and effects. NASSP Monograph, (October/November), 19-26.

Gregorc, A. F. (1985). Inside styles: Beyond the basics. Maynard, MA: Gabriel Systems.

Hawk, T. \& Shah, A. (2007). Using Learning Style Instruments to Enhance Student Learning, Decision Sciences. Journal of Innovative Education, 5(1).

Viola S., Graf, S., Kinshuk, F. \& Leo, T. (2007). Analysis of Felder-Silverman Index of Learning Styles by a Data-driven Statistical Approach. Journal of Research on Technology in Education, 40(1). 